\title{
Comparative Analysis of Medicines for Rural and Urban Population of Lithuania in 1935
}

\author{
Rita Perkamaitè and Vilma Gudienè \\ Faculty of Pharmacy, Department of Drug Technology and Social Pharmacy, Lithuanian University of Health Sciences, Kaunas, \\ Eiveniu g. 4, LT- 50161 Lithuania
}

Received: May 4, 2015 / Accepted: May 23, 2015 / Published: June 30, 2015.

\begin{abstract}
In order to answer the question as to how patients were treated in different historical periods, one of the most objective sources of study are pharmacy record books. The books were used for registration of all prescriptions based on which medicines have been produced in the pharmacy. Their contents reveal what medications were prescribed for treatment of various diseases, what kind of ingredients were used in the produce of medicines, and how much medicines cost. Lithuanian museums and archives stored dozen XIX-twentieth century the first half of prescription books. The present research analyses the prescription books of Petrašiūnai, a suburban area of the Lithuanian ${ }^{1}$ provisional capital, and a small Batakiai town in Taurage county with the population of 800 , in 1935 . Both books are stored in the Lithuanian Medical and Pharmaceutical History Museum. The study reveals what medicines were used for treatment of Lithuanian urban and rural residents in 1935, what the most often prescribed medicines were, specifics of the composition of medicines prescribed by doctors and a paramedic, popularity of animal medicines and the prices of medicines. The research was based on the methods of historical benchmark data processing and statistical analysis.
\end{abstract}

Key words: History of pharmacy, medicines therapy in 1935, medicines prescriptions.

\section{Introduction}

Changes in pharmacological therapy are revealed through a variety of historical sources, medicinal prescription books being some of the most informative ones. Analysis of their content reveals what medications were described by doctors and paramedics at that time for their patients. Population was buying prescription and non-prescription medicines and medical supplies in pharmacies. Forty percent of pharmacy revenue accounted for produced medicines. In the first half of the twentieth century, herbal medicines were increasingly often replaced by

Corresponding author: Rita Perkamaite, master of pharmacy, research fields: history of pharmacy and medicines prescriptions. E-mail: ritamicro@gmail.com.

1. The Pospolita (Polish-Lithuanian state), divided in 1795, after more than a century-long tsarist Russian annexation, Lithuania regained its independence in 1918. When Poland occupied Vilnius, Kaunas became the provisional capital Lithuania. In 1940, Lithuania was occupied by the Soviet Union. In 1990 Lithuania restored its independence, and since 2004 it is one of the 28 member states of the European Union. chemicals, and animal medicines became a rarity. In order to find out what medicines were used for treatment of urban and rural residents in the four decade of the twentieth century, analysis of the prescription books of Petrašiūnai, a suburban area of the Lithuanian provisional capital, and a small Batakiai town in Taurage County, managed by Jonas Pužauskas, were performed. The books are stored in the Lithuanian Medical and Pharmaceutical History Museum.

The aim of the research was to perform the comparative analysis of the composition, forms and prices of medicines produced in Petrašiūnai and Batakiai pharmacies in 1935 and to evaluate the differences between medications prescribed by doctors and a paramedic.

Tasks of the study:

(1). To evaluate the contents of medicines prescribed by Kaunas doctors and a paramedic from Batakiai; 
(2). To reveal the variety of forms and composition of components of the medicines produced in Petrašiūnai and Batakiai rural pharmacy;

(3). To evaluate the average price differences in Petrašiūnai and Batakiai pharmacies.

\section{Methodology}

The historical and comparative statistical analysis was used for the research. A total of 272 prescriptions recorded in January and June in Batakiai Jonas Pužauskas pharmacy and 283 prescriptions in Petrašiūnai Matas Valeika pharmacy, a total of 555 prescriptions, were analysed. Each prescription consists of several components. Seven hundred and ninety components from Batakiai book and 917 components from Petrašiūnai have been grouped into relevant parts: by pharmaceutical forms, by the origin of components (vegetable, mineral, animal, and chemical), distinguishing strongly acting substances and poisons (opium, mercury compounds, alkaloids etc.). The data obtained were compared applying the method of statistical analysis. Statistically significant was the difference (i.e., the difference between the criteria values), with the reliability of more than 95 percent (i.e., when $p<0.05$ ).

\section{Results and Discussion}

\subsection{Prescription Record Books}

Medicines could be prescribed to patients by doctors and paramedics. The latter had completed special courses and passed paramedic exams, while doctors had a university education. During the interwar Lithuania about $90 \%$ of all prescriptions in pharmacies were issued by doctors. Petrašiūnai pharmacy has records of 31 medical prescriptions, the vast majority of prescriptions were issued by doctors who practised in the capital city of Kaunas, and only a few of the recorded prescriptions were issued by county doctors. Medications were prescribed for Petrašiūnai residents not only by doctors of internal diseases but also by oculists, gynaecologists, specialists of nerves, skin diseases and others. Meanwhile, Batakiai prescription book only contains the prescriptions of the rural paramedic Kazys Rimša. It is likely that he earned the trust of people, because, for example, in 1923 the prescription book contains not only the prescriptions of paramedic Marošcikis who worked here, but another 30 doctors and paramedical personnel [1-3]. Thus, during the analysed period Batakiai residents consulted only with their rural paramedic.

Each prescription had to be recorded in a special registration book of prescriptions. It's sheets are numbered, bound, and the last page has a seal with the national emblem of the Health Department of the Ministry of Internal Affairs controlling pharmaceutical activities. Sheets in the book are divided into five sections: I. Month and day; II. Prescription sequence number; III. Prescription content; IV. Price, name of the physician or paramedic; VI. Patient's name.

One patient was often prescribed 2-3 medicines, combining oral and external, or oral medicines of several different forms. The quantity, and often the form is indicated for each component. While the source is in good condition and handwriting of pharmacists is legible, about $1 \%$ of the components still could not be identified $[1,2]$.

\subsection{Composition of Medicines}

Every doctor composed a medicinal product in their own way. Most of the medicines were comprised of three to four ingredients, but there are six (12 prescriptions in Petrašiūnai pharmacy, 8 in Batakiai), seven ( 2 prescriptions in Batakiai pharmacy) or even eight ingredients, one such prescription was reported in both prescriptions books. Potions of 8 parts prescribed by the internal medicine doctor Konstantinas Nekvedavičius and the Batakiai paramedic were comprised of three herbal and five chemical origin components $[1,2]$.

Most prescription medicines were oral (powders, 
infusions, decoctions, potions, pills etc.). The paramedic was usually prescribing oral medicines and only $7 \%$ of his prescribed medicines accounted for medicines for external use. In January, their proportion was higher by $10.4 \%$, but only $3 \%$ in June. More often, he would prescribe skin heating ointments for patients suffering from colds in addition to oral medicines. Meanwhile, Kaunas doctors often combined oral and external medicines, the latter accounted for $25 \%$ and also they moved often prescribed winter [1, 2]. The doctor A. Matulevičius was cracked skin ointment containing resorcine (Resorcini 0.3), sulphur (Sulfur praecipitati 5.0), zinc oxide (Zinci oxydi 3.0) and vaseline (Vaselini ad 20.0) [2].

According to the origin of the raw materials, components are divided into herbal, animal, chemical and mineral. Interestingly, doctors gave priority to herbal components and the paramedic to chemical medicines. Petrašiūnai book has records of $48.2 \%$ herbal and $49.2 \%$ chemical ingredients, and Batakiai-40.5\% herbal, and $55.6 \%$ chemical. Animal medicines accounted for only about $3 \%$, and were more often prescribed by the paramedic $[1,2]$.

Both paramedics and doctors could prescribe strongly acting substances but paramedics were allowed to prescribe only half of the maximum permissible dose. Thus, both prescriptions books have records from the so-called " $\mathrm{A}$ " list of medicines: strychnine tincture (Tinct. Strychni), caffeine sodium benzoate and codeine phosphate $[1,4]$.

\subsection{Herbal Medicines}

The popularity of herbal medicines declined and they were replaced by chemical compounds. In 1830, herbal medicine ingredients registered in Telšiai prescription book accounted for 71\% [5], in 1923 in Batakiai pharmacy-for about 60\% [3] and in 1935 herbal components accounted for $45 \%$. In 1935, the prescription book mentions 40 different plants. A variety of pharmaceutical forms of medicines were made of roots, leaves, fruits, seeds, resins - infusions, decoctions, tinctures, extracts and oils.

Tropical plants and galenical preparations from them were prescribed much more frequently than local, they included condurango bark (Cortex Condurango), cinchona bark (Cort. Chinae), ipecac roots (Radix Ipecacuanhae), common marshmallow (Althaea officinalis). For example, out of 34 prescriptions recorded by Andrius Matulevičius in January even 13 had senega snakeroot (Senega). In Petrašiūnai prescription book imported herbal raw materials accounted for $77.9 \%$, and in Batakiai 64\%. However, paramedic K. Rimša often would prescribe parts of plants growing in Lithuania, such as valerian root (Radix Valerianae), black henbane leaves (Fol. Hyoscyamus niger), rhubarb roots (Rad. Rhei), mint leaves (Fol. Menthae), juniper fruit (Fructus Juniperi), lily of the valley herb (Herba Convallariae), which accounted for $36 \%$, while in Petrašiūnai pharmacy-22.1\%.

In the production of medicines herbal components were usually mixed with chemicals. For example, cough mixture usually contained spring pheasant's-eye infusion (Inf. Adonidis vernalis 6.0), ipecac root infusions (Inf. Rad. Ipecacuanhae 0.5 ad 180), anise drops (Liq. Ammonni anisati 4.0), sodium benzoate (Natrii benzoici 3.0) and codeine phosphate (Codeini phosphorici 0.2), and rheumatic pain medications were treated with alcohol solution consisting of mustard spirits (Spiritus Sinapis), formic spirit (Spiritus Formicari), soap spirit (Spiritus Saponati) and henbane oil (Ol. Hyoscyamus) [2].

The medicines often included anise drops (Liq. Ammonii anisati) consisting of anise oil, ammonia and alcohol used as an expectorant and providing a pleasant smell to the medicine [6]. Potions had a combination of snakeroot extract (Decoct. rad. Senegae), having mucolytical properties or ipecac infusion (Inf. rad. Ipecacuanhae), an effective means helping to eliminate viscous mucus. Medicines were produced from small woody liana-condurango (Gonolobus condurango). Plant bark tincture is 
valuable for relieving stomach pain, improving digestion and inhibiting nausea and vomiting [3]. Often, it was prescribed in combination with tinctures of china (Tinct. Chinae) and rhubarb (Tinct. Rhei). Sometimes multiple medicines known after specific name consisting of a few components, were prescribed. For example, in January in Petrašiūnai pharmacy a compound preparation Tincture Amara was registered, it contained citrus fruits (Fruct. Aurantii) centaury grass (Herbae Centauri minoris), gentian root (Rad. Gentianae) and turmeric rhizome (Rhiz. Zedoariae) [2, 4]. Heart diseases are often treated with spirit herbal tincture of the lily of the valley (Tinct. Convallariae majalis) often in combination with tinctures valerian and strophanthus seeds (Tinct. Strophanthae). Sometimes heart drops containing the tinctures of lily of the valley, strychnos fruit (Tinct. Nucis Vomicae) and foxglove (Tinct. Digitalis) were prescribed [2]. Ergot (Extr. Secalis cornuti) has been used to stop bleeding, suppress migraine headaches and for treatment of female diseases. Sometimes it was combined with the active substance of hop cones lupulin (Lupulin) [2]. Juniper berry intrusion (Inf. fructi Juniperi) has been used to stimulate urine secretion and improve intestinal activity. Decoctions were used to treat joint inflammation. It is interesting to note that this conifer is only mentioned in Batakiai prescription book [1].

Petrašiūnai pharmacy made four medicines containing opium. The paramedic did not prescribe medicines with opium to his patients. Meanwhile, in 1923 as much as 6\% medicines made in Batakiai contained this narcotic substance. In the XIX century opium was one of the most popular medicines to suppress pain, fever, used as a sedative and was recommended for treating coughs. Among medicines with opium made in Petrašiūnai pharmacy were Tinctura opii simpl., Extractum Opii and Tinctura Opii benzoica - this is opium tincture with anise oil (Olei Anisi vulg.), camphor, benzoic acid (Acidi benzoici) and wine [4]. Opium tincture for internal use with ipecac root infusion, anise drops and altea syrup was given for cough. Petrašiūnai pharmacy has registered a suppositories prescription with opium alkaloid papaverine (Papaverini). Often, Kaunas doctors and the paramedic prescribed opium alkaloid codeine to their patients, which was included in the composition of cough mixtures in conjunction with snakeroot root decoction (Dec. rad. Senegae) anise drops (Liq. Ammonii anisati), potassium sulfogaiacol (Kalii sulfoguajacoli), caffeine sodium benzoate (Coffeini natrii benzoici) and (Sirupi simplicis) sugar syrup [2].

\subsection{Chemical Medicines}

Very large proportion of ingredients were mineral salts, acids, and synthetic organic compounds. In total, pharmacists have been using over 100 chemicals. Salts are mentioned most often in prescription books: potassium bromide, calcium bromide, potassium chloride, sodium bicarbonate zinc sulfate potassium and sodium iodides, sodium bromide, sodium chloride, calcium and sodium phosphates. Potassium iodide and sodium salts have mucolytical, expectorants effects, and were also used externally for skin fungal diseases. Batakiai paramedic issued 19 prescriptions with iron iodide syrup, Kaunas doctors did not offer this medicine. Petrašiūnai pharmacy made 3 prescriptions with potassium iodide. In 1935 the following toxic mercury compounds were used in medical practice for treatment: Hydrargyrum praecipitatum, Hydrargyrum oxycyanati $[1,2]$. Mercury salts and oxides were used as disinfectants in patients with gonorrhea, conjunctivitis and infectious skin diseases. In January doctor A. Kryževičius issued mercury ointment Ung. Hydrargyri flavi $1 \% \quad 5.0$ as an antiseptic [2]. In Petrašiūnai prescription book, silver protein, Argenti proteinici, found in nasal drops as frequently prescribed together with suprarenin. The solution of strongly operating substance silver nitrate, Argenti nitrici, was still used as an antiseptic. For the production of medicines by pharmacists used 
inorganic sulfuric and boric acids. Sulfuric acid has been intended for oral use (1 prescription in Petrašiūnai pharmacy), and boric acid solution (3 prescriptions in Batakiai and Petrašiūnai pharmacies) was an integral part of eye drops. Only once Petrašiūnai prescription book recorded organic acetic acid Acidum aceticum, used to treat fever and weakened patients [5]. It was used in combination with camphor and turpentine and pine oils. Sulphur, Sulfuris depurati, found in skin ointments. Iron iodide, Ferrum iodatum, used for infectious disorders. Sometimes salt was prescribed for subcutaneous injection in ampoules Natrii kakodylici with arsenic [2].

There are a number of synthetic compounds in medicines: salicylic acid and its salt sodium salicylate, acetylsalicylic acid (aspirin), phenacetin, pyramidon, anesthesine, pantocaine. Petrašiūnai pharmacy prescriptions organic salicylic acid, integral part of skin liniments, with antibacterial and anti-inflammatory effects, and sodium salicylate was used orally. Other compounds were mostly composite powder components. Phenacetin combined with acetylsalicylic acid, amidopyrine with caffeine sodium benzoate, other substances were combined with tinctures and bromides. Most often such combinations of medicines were made by the pharmacist for colds, rheumatism or pain [1-3].

Prescription books have also more specific materials having certain effect. In five prescriptions produced by Petrašiūnai pharmacy they mention Dover powder, Pulvis Doweri also known as Pulvis Ipecacuanhae opiatus. This mixture ipecac root (Radix Ipecacuanhae) opium (Opium purum) and potassium sulphate. Powder promoted sweating and decreased pain [2]. Prescriptions contain several mentions of a particularly poisonous $1 \%$ potassium arsenite solution Liquor arsenicalis Fowleri. Since 1845 it has been used to treat leukemia, malaria, syphilis and chorea $[1,2,7]$. Batakiai prescription book recorded a composite powder Pulvis Liquiritiae compositus, in literature, it has the following composition: Sennae Folia pulverisata, Liquiritiae Radix pulverisata, Foeniculi Fructus pulverisatum, Sulfur Sublimatum, Saccharum Purificatum pulverisatum $[1,4]$. The paramedic most likely was prescribing them for constipation.

In 1935 the most popular narcotic medicines was morphine and cocaine. Doctor A. Kryževičius issued seven prescriptions with morphine hydrochloride ampoules, Morphinum Muriaticum [2]. In Kaunas Petrašiūnai prescription books two prescriptions were found with synthetic cocaine substitute, Beta-Eucaini. The anesthetic was prescribed for dental pain, ophthalmology or renal dysfunction $[1,3]$. Sterile injectable solution was produced: B-Eucaini 0.08, Sol. Natrii chlorati 0.8\%-80.0 Steril (Fig. 1) [2]. Very rarely pantopon was mentioned (Pantoponi) a mix of opium alkaloids hydrochlorides containing about $50 \%$ of morphine. In one prescription from Petrašiūnai book it was issued in the form of suppository and in the other in drops. It was used as a painkiller and soporific medicine [2, 4].

Petrašiūnai pharmacy has prescriptions with 8 dispensed powder where semi-synthetic codeine derivative-Eucodal. Often it were these combinations: Eucodali 0.065, Phenacetini 0.3, Acidi acetylsalicylici 0.35 or Eucodali 0.006, Extr. Belladonnae 0.02, Magnesii perhydroli, Saloli a a 0.3. It was an effective pain relief. Such pharmaceutical prices were very high,

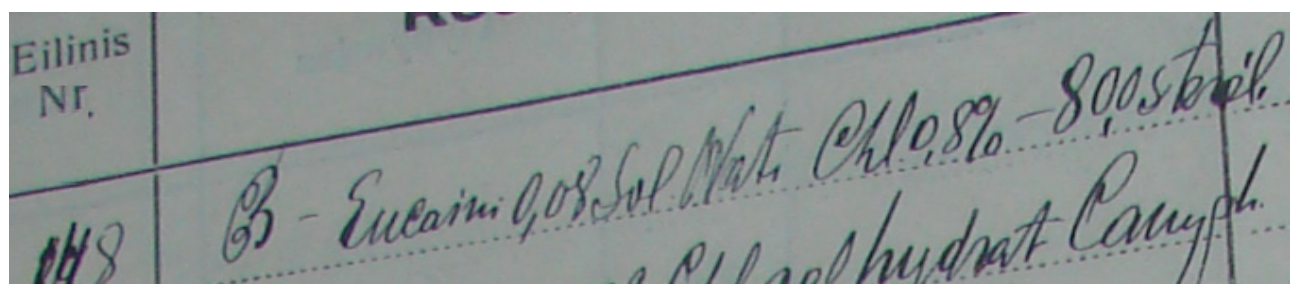

Fig. 1 Prescription with cocaine (B-Eucaini 0.08; Sol. Natrii chloridi 0.8\%-80.0 Steril.) Petrašiūnai prescription book 1935. 
from 3 to 5.1 litas [2]. Another natural opium alkaloid-codeine, was included in medicinal preparations for cough. In potions it was prescribed in conjunction with thyme syrup (Sirupi Thymi comp.), valerian root sauce (Inf. rad. Valerianae) or snakeroot root decoction. Sometimes codeine (Codeini puri) was prescribed in powder form together with sugar [1, 2].

In the first half of the twentieth century, narcotic substances were use very often although they did not exceed the permissible doses. In Batakiai village pharmacy about $9 \%$, while in Petrašiūnai-13\% prescription medicines were produced using narcotic substances. Thus, these substances were still abundantly used without the knowledge of their damage.

\subsection{Animal Medicines}

In the beginning of the nineteenth century medicines containing animal material were still popular. In 1830 Telšiai prescription book they accounted for $6 \%$ of all components. Most of them, patch was prescribed Emplastrum Vesicatorii, containing Spanish fly powder Cantharides, as well as essence and tincture from beaver wisp Castoreum, bee products.

Meanwhile, in 1935, substances of animal origin from pigs, beaver, ants ere mentioned in Petrašiūnai and Batakiai prescription books very rarely. Medicines from beaver wisp Castoreum were found only in one doctor's prescription. It is pungent-smelling, yellowish red powder from beaver tail gland. Formic spirits Spiritus Formicarum, in external medicines was used for rubbing in patients with joint disease.

By origin, this group also contains adrenaline, a key component of eye drops. It has been synthesized in the laboratory and was delivered to pharmacies in the form of suprarenin- $-0.1 \%$ adrenaline solution. Oculist prescribed medications with zinc sulfate, adrenaline and mercury: Zinci sulfurici 0.03 Sol. Adrenalini 1:1000 gtt. X and Sol. Hydrargyri oxycyanati 1:10000 ad 10.0 [2]. Batakiai prescription book sometimes mentions Pepsinum germanicum - the soluble pepsin powder form $[1,2]$. In 1935, prescription books no longer contain Spanish fly tincture (Tinct. Cantharicum). However, in 1923 Batakiai book mentioned this medicine more than once, as having topical irritant effects. When mixed with alcohol and castor oil it was prescribed for hair loss [3].

In the third decade of the twentieth century there were only a few animal medicines left. They were pushed by popular chemical compounds-codeine phosphate, caffeine sodium benzoate, anesthesine, phenacetin and others.

\subsection{Pharmaceutical Forms}

Pharmacies were selling medicines two residents produced according to prescriptions, and medicines made in Lithuanian and foreign pharmaceutical companies. About $40 \%$ of pharmacy revenue accounted for their produced medicines: powders, pills, ointments, potions, suppositories, extracts, tinctures, herbs and other.

Both pharmacies offered accurately produced oral dosage forms: powders, pills, suppositories and potions, syrups, suspensions, emulsions, drops, infusions and decoctions. For external use: ointments, liniments, oils, solutions, eye drops.

The most common were liquid oral forms of medicines-potions. In Batakiai pharmacy they accounted for $15.4 \%$, in Petrašiūnai pharmacy $16.1 \%$ of all medicines. The second most popular medicines form was powder. Batakiai village pharmacy made $12.5 \%$, and Petrašiūnai pharmacy slightly less $-8.8 \%$ of them. Ointments in Petrašiūnai pharmacy accounted for $2.4 \%$ and in Batakiai pharmacy for $2.2 \%$ medicines. Batakiai pharmacy usually produced ichthyol ointment, Ung. Ichtyoli, while Petrašiūnai pharmacy did not make it $[1,2]$.

Rarely prescribed were pills and suppositories. Petrašiūnai pharmacy recorded 8 prescriptions of pills and 5 suppositories and Batakiai pharmacy 4 prescriptions of pills and 3 of suppositories. Pills often contained components affecting blood-forming organs 
with iron and arsenic, for the treatment of anemia Pil. Blaudi (Fig. 2). Petrašiūnai pharmacy had greater variety of medicine forms produced. Prescription book as records of 2 ampoules, one tablets (Santonini tab.), 8 liniments, 6 eye drop prescriptions. These forms of medicines were not made in Batakiai pharmacy.

In 1935 in both rural and urban pharmacies were making various pharmaceutical forms while doctors were increasingly often prescribing patent medicines produced in Lithuanian and foreign pharmaceutical factories.

\subsection{Medicine Prices}

Medicines prices in 1935 were regulated by the official publication Vaistu taksa issued by Health Department. It contained all prices of medicine components and cost per job (Taxa laborum). The pharmacist could reduce the price of medicines. However, the Vaistu taksa prohibited to announce discounts for medicines [4]. Prices of medicines were indicated in litas (monetary unit).

During January and June 1935 Petrašiūnai pharmacy earned for prescription medicines 716.59 litas, while Batakiai town pharmacy and less -692.07 litas. The research revealed that the prices of medicines in the pharmacies of Batakiai (LTL 2.55) and Petrašiūnai (LTL 2.54) had no statistically significant differences $(\mathrm{P}=0.597>0.05)$. The cheapest medicine in Petrašiūnai pharmacy was sold for LTL 0.5, the most expensive for LTL 7.0, and in Batakiai village pharmacy the cheapest was sold for LTL 0.75, the most expensive for LTL 6.55. For comparison it may be noted that at the time a matchbox cost 10 cents, while a kilo of meat LTL 1 .
Most expensive were medicines containing expensive imported animal raw materials-Castoreum, as well as vegetable raw materials from South America and Asia-Condurango, Cortex Chinae. The medicines of three chemical components containing powder Eucodali 0.012, Luminali 0.05 and caffeine cost LTL 6.75 [2]. The price depended on the number of components, cost of raw materials, complexity of production and form of medicine. It should be noted that prescription books only recorded the total amount of medicines without indicating the costs of ingredients, packaging or work, as was instructed in the Vaistu taksa [1,2].

The study revealed that rural pharmacy had significantly cheaper cost $(p<0.05)$ than in urban pharmacy for aqueous solutions, their average price being LTL 1.41, drops-LTL 2.21 and ointments-LTL 1.79. Petrašiūnai pharmacy significantly cheaper mixtures were available, with an average price reaching 2.53 litas. Prices of other forms of medicines in Batakiai and Petrašiūnai pharmacies were slightly different, but these differences were not statistically significant $(p>0.05)$. The highest price in Petrašiūnai pharmacy was for suppositories LTL 3.08, liniments LTL 3.03 and powder 3.07 litas. Higher costs in the rural pharmacy were for pills LTL 2.56, emulsions LTL 3.70, suspensions 2.90 litas (Fig. 3) [1, 2].

The evaluation of average prices for oral and external medicines in the rural and urban pharmacies it was found that the prices of oral and external medicines differed only in Batakiai pharmacy $(\mathrm{P}=0.000<0.05)$ it revealed that oral medicines were much more expensive in this pharmacy, with the price average reaching LTL 2.64 compared to external medicines

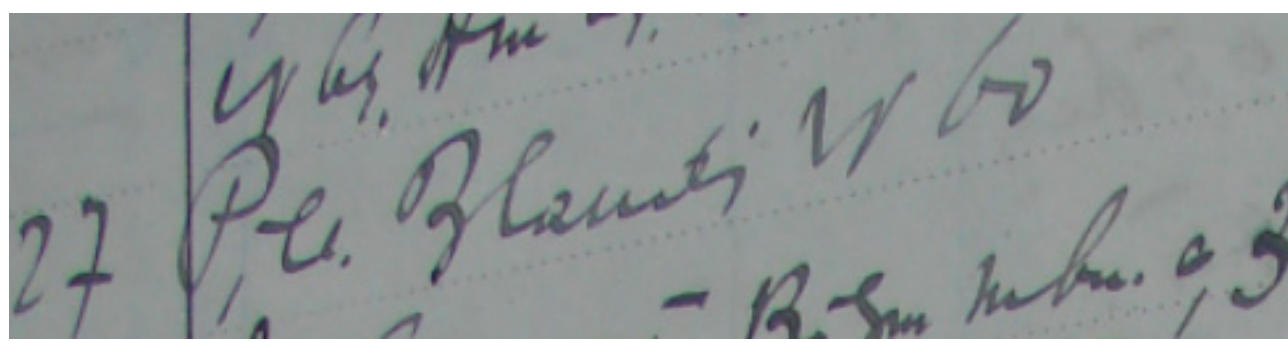

Fig. 2 Iron carbonate pills prescription (Pilulae Blaudi N. 60) Batakiai prescription book, 1935. 


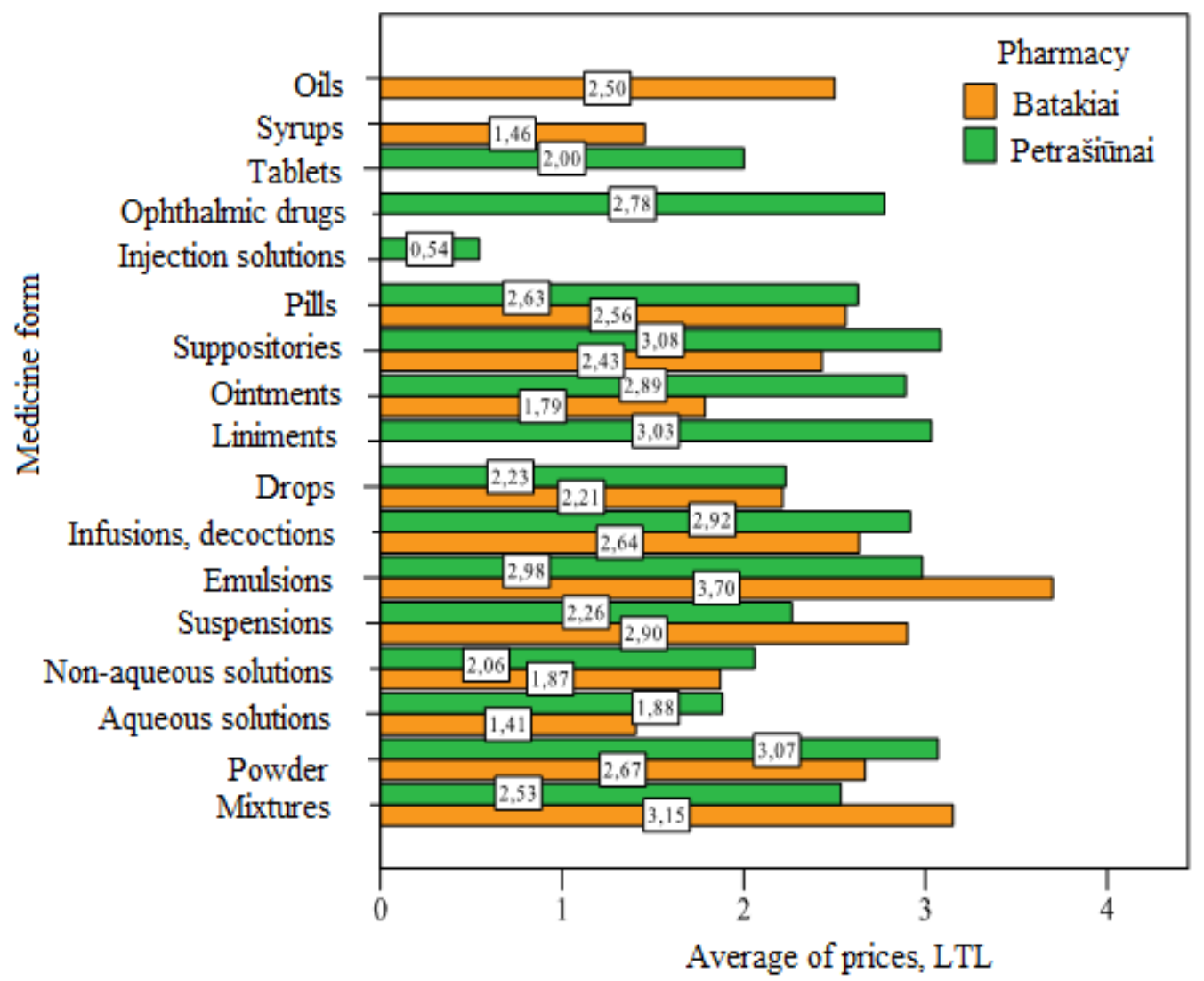

Fig. 3 Prices of medicine forms in Petrašiūnai and Batakiai pharmacies in 1935.

with price average of 1.64 litas. Meanwhile, in Petrašiūnai pharmacy oral and external medicines cost similar, i.e. accordingly LTL 2.51 and LTL $2.54(\mathrm{P}=$ $0.743>0.05)$.

The price for mixing of fluids, reconstitution, dissolving and mixing of any number or quantity was LTL 0.75, and mixing fine and coarse powder cost LTL 0.75. Filling and sealing of glass ampoules without sterilization, mixing and dissolving, per ampoule was 0.15 LTL. Forty cent was the cost of the plug, the label, packaging, marking, sealing, wrapping [5].

Therefore, medicines were expensive. Based on Vaistu taksa, premium for work in Petrašiūnai and Batakiai pharmacies accounted for about $50 \%$ of the price of most medicines.

\section{Conclusions}

(1). Paramedic of Batakiai, like Kaunas doctors, was prescribing medicines similar in their content and dosage form, only at lower doses. Petrašiūnai pharmacy preferred expensive in imported raw materials well Batakiai village pharmacy used much less of them.

(2). Batakiai rural pharmacy produced 13 different forms of medicines according to 272 prescriptions of the paramedic, Petrašiūnai pharmacy-15 forms of medicines according to 283 prescriptions by doctors.

(3). Pharmacies offered similar products, their ingredients and prices.

\section{References}

[1] Pužauskas, J. 1929-1935. Lithuanian Medicine and Pharmacy History Museum Funds. The Prescription Book of Batakiai Pharmacy.

[2] Valeika, M. 1934-1935. The Prescription Book of Petrašiūnai Pharmacy. Lithuanian Medicine and Pharmacy History Museum funds.

[3] Mitrikevičiūtè, K. 1923. "Analysis of Prescription Books 
of Batakiai Pharmacy in 1923." Final Master's thesis, Kaunas University of Medicine.

[4] Official publication of Health Department. Kaunas. Lithuania. 1935. "Vaistų taksa".

[5] Gudienè, V., and Šimaitienè, Z. 2014. "Medicines Produced in Telšiai Pharmacy (Vilnius Governorate): Analysis of Prescription Book from 1830.” Pharmazie 69
(1): 76-80.

[6] Lithuanian Pharmacopoeia. Kaunas. Lithuania. 1938.

[7] Chen, S. J., Zhou, G. B., Zhang, X. W., Mao, J. H., de The, H., and Chen, Z. 2011. "From an Old Remedy to a Magic Bullet: Molecular Mechanisms Underlying the Therapeutic Effects of Arsenic in Fighting Leukemia." Blood 117 (24): 6425-37. 